\title{
Avaliação do desempenho do método do ensaio por enzimas imuno-adsorvidas (ELISA) em leite em pó reconstituído contaminado experimentalmente com aflatoxina $M_{1}^{*}$
}

\section{Evaluation of competitive enzyme-linked immunosorbent assay (ELISA) in milk powder contaminated with known concentrations of aflatoxin $M_{1}$}

\author{
Carlos Augusto Fernandes de Oliveira e Pedro Manuel Leal Germano \\ Departamento de Produção Animal da Faculdade de Medicina Veterinária e Zootecnia da \\ Universidade de São Paulo. São Paulo, SP - Brasil (C.A.F.O.), Departamento de Prática de Saúde \\ Pública da Faculdade de Saúde Pública da Universidade de São Paulo. São Paulo, SP - Brasil \\ (P.M.L.G.)
}

\begin{abstract}
Resumo
O desempenho do ensaio por enzimas imuno-adsorvidas (ELISA), mediante o emprego de conjuntos de reativos produzidos em escala comercial, para determinação de aflatoxina, foi avaliado em condições experimentais, através de análises repetidas, em amostras de leite em pó reconstituído contaminadas com concentrações conhecidas da fração $M_{1}$ da toxina. Para os níveis de 0,$10 ; 0,20 ; 0,50$; e, $1,00 \mathrm{ng} / \mathrm{ml}$, os percentuais de recuperação foram: 83,0\%; 87,5\%; 103,0\%; e, $111,8 \%$, respectivamente. O desvio-padrão relativo, para as referidas concentrações, foi, respectivamente, $65,5 \% ; 31,8 \% ; 10,9 \%$ e $13,6 \%$ (n=10, para cada nível de contaminação). Os resultados obtidos demonstram que o método é apropriado para pesquisas e levantamentos sobre a ocorrência de aflatoxina $M_{1}$ em leite, sobretudo nas faixas de concentração entre $0,20-1,00 \mathrm{ng} / \mathrm{ml}$.
\end{abstract}

Substitutos do leite humano, toxicidade. Aflatoxina $M_{1}$. ELISA.

\begin{abstract}
The evaluation of commercially available test systems of competitive enzymelinked immunosorbent assay (ELISA), for Aflatoxin $M_{1}\left(A F M_{1}\right)$ was performed in experimental conditions, through repeated analysis, in samples of milk powder contamined with known concentrations of the toxin. Recoveries of
\end{abstract}

\footnotetext{
*Extrato da tese de doutorado intitulada "Aflatoxina $\mathrm{M}_{1}$ em leite em pó distribuído pelo programa de alimentação escolar no Município de São Paulo, SPBrasil: utilização do ensaio por enzimas imuno-adsorvidas (ELISA)", apresentada à Faculdade de Saúde Pública da Universidade de São Paulo, 1994. Correspondência para/Correspondence to: Pedro Manuel Leal Germano - Departamento de Prática de Saúde Pública da Faculdade de Saúde Pública da Universidade de São Paulo. Av. Dr. Arnaldo, 715 - 01246-904 São Paulo, SP - Brasil - Fax: (011)883.3501

Edição subvencionada pela FAPESP. Processo 95/2290-6.

Recebido em 18.12.1995. Aprovado em 3.4.1996.
} 
$A F M_{1}$ added to milk at levels of $0.10,0.20,0.50$ and $1.00 \mathrm{ng} / \mathrm{ml}$ were $83.0 \%$, $87.5 \%, 103.0 \%$ and $111.8 \%$ respectively. Relative standard deviations for the above mentioned concentrations were $65.5 \%, 31.8 \%, 10.9 \%$ and $13.6 \%$, respectively ( $n=10$, per spiking level). According to these results the ELISA is appropriate for $A F M_{1}$ research and/or surveying, mainly for concentrations between $0.20-1.00 \mathrm{ng} / \mathrm{ml}$.

Milk substitutes, toxicology. Aflatoxin $M_{I}$ ELISA.

\section{INTRODUÇÃO}

A aflatoxina $M_{1}\left(\mathrm{AFM}_{1}\right)$ é um potente hepatocarcinógeno excretado no leite de vacas alimentadas com rações contaminadas com aflatoxina $\mathrm{B}_{1}$, principal metabólito produzido por fungos do gênero Aspergillus $^{26,29}$. A contaminação do leite de consumo humano por $\mathrm{AFM}_{1}$ assume destacada relevância em saúde pública, ao se considerar que seus efeitos tóxicos e carcinogêncios têm sido extensivamente demonstrados em diversas espécies, sobretudo em animais jovens ${ }^{3,11,26,27}$. Conseqüentemente, torna-se indispensável a adoção de técnicas analíticas exequiíveis e confiáveis para a detecção e controle desta toxina no leite ${ }^{20}$. Este fato reveste-se da maior importância com relação ao leite em pó, dada a sua ampla utilização, no Brasil, em programas destinados à suplementação alimentar de crianças da rede escolar pública.

Os primeiros métodos para a determinação de $\mathrm{AFM}_{1}$, em amostras de leite e derivados, foram desenvolvidos em meados dos anos 60 , tendo como base a propriedade fluorescente da toxina, quando exposta à luz ultra-violeta ${ }^{15}$. Deste modo, a técnica de identificação e quantificação utilizada de início, e ainda largamente empregada na atualidade, foi a cromatografia de camada delgada $(\mathrm{CCD})^{15}$. Posteriormente, com o desenvolvimento dos métodos por cromatografia líquida de alta resolução (CLAR), houve um incremento notável no grau de precisão das análises, porém, com o aumento significativo dos custos das análises ${ }^{2,23}$.

No início da década de 80 surgiu uma nova perspectiva para a análise de aflatoxinas, com a introdução dos métodos imunoquímicos, ou imunoensaios, fundamentados nas reações específicas entre anticorpos e antígenos, com destaque para os de radioimunoensaio, cromatografia de imunoafinidade e de ensaio por enzimas imuno-adsorvidas (ELISA) ${ }^{8}, 18$. O método de ELISA, do tipo direto, porém, é um dos mais utilizados, principalmente para $\mathrm{AFM}_{1}^{20}$, onde a cor resultante das soluções pode ser comparada mediante observação visual, com padrões conhecidos, em testes qualitativos ${ }^{13,16,25}$, ou por espectrofotometria, para a obtenção de resultados quantitativos ${ }^{17}$.

Existem, atualmente, conjuntos de ELISA, produzidos em escala comercial, para a execução de análise de aflatoxinas em alimentos ${ }^{18}$. Esses sistemas são de execução simples, e podem ser empregados diretamente nas amostras, uma vez que não requerem etapas de purificação devido às altas especificidade e sensibilidade dos anticorpos ${ }^{14}$. Esta característica representa uma vantagem considerável do método especialmente em relação à análise de $\mathrm{AFM}_{1}$, em leite e derivados, pois permite a sua aplicação em grande número de amostras, em intervalo de tempo relativamente pequeno, o que não ocorre com os métodos cromatográficos ${ }^{14}$. Para o leite "in natura", o método de ELISA, assim aplicado possibilitou a Pestka e col. ${ }^{19}$ (1981) a detecção de AFM, a partir de $0,25 \mathrm{ng} / \mathrm{ml}$.

Scott ${ }^{20}$ (1989), em revisão sobre os métodos quantitativos aplicados à análise de $\mathrm{AFM}_{1}$, em leite e derivados, concluiu que os ensaios de ELISA têm apresentado desempenho satisfatório, inclusive em faixas de concentração ao nível de partes por trilhão (ng/ml). Entretanto, o autor não encontrou referências sobre a realização de estudos interlaboratoriais para a confirmação desses resultados. Por esse motivo, considera-se fundamental a adoção de procedimentos para a avaliação do desempenho deste método, previamente à sua aplicação no laboratório ${ }^{6}$. Esta necessidade é reforçada em razão dos conjuntos de ELISA requererem condições especiais de conservação, pois como material biológico são sensíveis às variações de temperatura que podem ocorrer, em especial, durante o transporte e armazenagem ${ }^{8}$.

O objetivo do presente trabalho é avaliar o desempenho do método de ELISA, quantitativo frente a amostras de leite em pó reconstituído, contaminadas experimentalmente com $\mathrm{AFM}_{1}$. 


\section{MATERIAL E MÉTODO}

\section{Amostras}

Foram utilizadas $62,5 \mathrm{~g}$ de leite em pó integral divididas em 5 amostras de igual quantidade. Reconstituiu-se cada amostra de leite em pó através da diluição de $12,5 \mathrm{~g}$ em $100 \mathrm{ml}$ de água destilada, previamente aquecida a $40^{\circ} \mathrm{C}$.

A comprovação da ausência de quantidades detectáveis da toxina foi realizada em laboratório de controle de qualidade, após 3 análises negativas pelo método ZCI (Zuivelcontroleinstitut), sumarizado por $\operatorname{Scott}^{20}$ (1989). Este método foi submetido a estudo interlaboratorial na Holanda, e apresenta, como limite de detecção, $0,1 \mu \mathrm{g} / \mathrm{kg}$ de leite em pó ${ }^{20}$.

\section{Determinação da Concentração do Padrão de Aflatoxina M1}

O padrão de $\mathrm{AFM}_{1}$ com $5 \mu \mathrm{g}$, depois de dissolvido em volume conveniente de clorofórmio p.a. $(3,0 \mathrm{ml})$, foi calibrado espectrofotometricamente através da técnica preconizada pelo Tropical Development and Research Institute $^{24}$ (1984). A solução padrão, assim preparada, contendo $1,74 \mu \mathrm{g} / \mathrm{ml}$ da toxina, foi utilizada para a preparação das amostras contaminadas com $\mathrm{AFM}_{1}$.

\section{Preparação das Amostras}

Para a adição da $\mathrm{AFM}_{1}$ às amostras de leite reconstituído, adotou-se o procedimento utilizado por Della Rosa ${ }^{4}$ (1979) para a contaminação experimental de leite "in natura" com AFM . A solução padrão foi, então, transferida para frascos volumétricos de $100 \mathrm{ml}$, numerados de 1 a 5 , correspondendo o primeiro ao controle, sem $\mathrm{AFM}_{1}$. Os demais continham: $5,8 \mu \mathrm{l}$ o segundo; $11,5 \mu \mathrm{l}$ o terceiro; $28,8 \mu \mathrm{l}$ o quarto; e, $57,5 \mu \mathrm{l}$ o quinto.

Na sequiência do método, o conteúdo dos frascos foi evaporado até a secagem total, sob fluxo de nitrogênio. Em seguida, transferiu-se $100 \mathrm{ml}$ do leite reconstituído (aquecido a $40^{\circ} \mathrm{C}$ ) para um dos frascos, sob agitação constante, através da adição de alíquotas de $25 \mathrm{ml}$, com intervalos de 5 min entre cada uma, até completar o volume. Assim, os frascos de 1 a 5 passaram a conter uma concentração estimada da $\mathrm{AFM}_{1}$ da ordem de zero; 0,10; 0,20; 0,50 e $1,00 \mathrm{ng} / \mathrm{ml}$, respectivamente.

\section{Análise das Amostras}

As amostras preparadas foram analisadas, por um mesmo técnico, através do método de ELISA quantitativo para $\mathrm{AFM}_{1}$, mediante a utilização de conjuntos de reativos comercialmente produzidos (Veratox ${ }^{\mathrm{TM} \circledast}$ ). Previamente à execução dos ensaios, as amostras foram submetidas à centrifugação a $3.000 \mathrm{rpm}$, por $15 \mathrm{~min}$, para a remoção e descarte da camada sobrenadante de gordura. Estabeleceram-se 10 análises para cada amostra, com a finalidade de possibilitar o processamento estatístico dos resultados obtidos, para cada nível de contaminação de $\mathrm{AFM}_{1}$.

\section{Preparo das Soluções}

Os padrões de $\mathrm{AFM}_{1}$ que acompanham os conjuntos de reativos encontram-se dissolvidos em uma matriz de leite liofilizado, distribuídos em 5 frascos. Para a sua reconstituição, acrescentou-se 2,0 ml de água destilada a cada um dos frascos, seguido de agitação vigorosa. A estabilização completa destas soluções foi alcançada, somente uma hora após a sua preparação, cujas concentrações foram: $0 ; 0,25 ; 0,50 ; 1,00$ e $2,00 \mu \mathrm{g} / \mathrm{ml}$.

$\mathrm{O}$ substrato foi preparado misturando-se 8 partes de tetra-metil-benzidina com uma parte de solução de $\mathrm{H}_{2} \mathrm{O}_{2}$. $\mathrm{O}$ substrato deve ser armazenado em local protegido da luz até o momento de utilização, sendo que sua durabilidade é de 4 - 8 horas. Os demais reativos utilizados nos ensaios foram fornecidos prontos para o uso.

\section{Execução do Ensaio}

Em cada seqüência analítica, removeu-se uma microcubeta de mistura para cada amostra, bem como 5 microcubetas para os padrões, colocando-as no suporte. Removeu-se um número igual de microcubetas cobertas com anticorpos. Deste modo, procedeu-se à análise simultânea das 5 amostras em cada sequiência analítica, repetindo-a 10 vezes, de maneira a completar 10 análises para cada amostra.

Os ensaios foram conduzidos mediante a execução das seguintes etapas: em cada uma das microcubetas de mistura, colocou-se $50 \mu \mathrm{l}$ do conjugado; pipetou-se $200 \mu \mathrm{l}$ dos padrões e das amostras, nas microcubetas respectivas; após homogeneização, transferiu-se rapidamente, com o auxílio de pipeta multicanal, $100 \mu$ l do conteúdo de cada microcubeta de mistura para a correspondente microcubeta coberta com anticorpos, descartando-se as contendo a mistura. Após período de repouso de $30 \mathrm{~min}$, à temperatura ambiente, as microcubetas foram lavadas delicadamente com água destilada e colocadas, na posição invertida, sobre papel absorvente, para a secagem; pipetou-se 100 $\mu l$ do substrato em cada microcubeta; após nova homogeneização, as microcubetas foram deixadas em repouso adicional por $10 \mathrm{~min}$, à temperatura ambiente; e, pipetou-se $100 \mu \mathrm{l}$ da solução estabilizadora em cada microcubeta, seguida de nova homogeneização.

\section{Leitura Espectrofotométrica e Interpretação dos Resultados}

Procedeu-se à mensuração da absorbância do conteúdo das microcubetas, em leitora própria para ensaios pelo método de ELISA, utilizando filtro de $650 \mathrm{~nm}$, considerando o ar como branco.

Os valores de absorbância dos padrões de 0,$25 ; 0,50$; 1,00 e $2,00 \mu \mathrm{g} / \mathrm{ml}$ foram submetidos ao procedimento descrito por Park e col. ${ }^{17}$ (1989), para o cálculo dos percentuais de desenvolvimento de cor em relação ao padrão zero. Os resultados, assim obtidos, foram plotados graficamente em papel Logistic-Log, no eixo Y, juntamente com as respectivas concetrações, no eixo $\mathrm{X}$, para estabelecimen- 
to da curva de calibração. As concentrações de $\mathrm{AFM}_{1}$, nas amostras foram expressas em $\mathrm{ng} / \mathrm{ml}$ de leite reconstituído.

\section{Análise Estatística}

Os resultados obtidos nas análises foram submetidos a tratamento estatístico para o cálculo da média, desvio padrão e desvio padrão relativo (coeficiente de variação) ${ }^{5}$ com a finalidade de verificar a precisão do método de análise frente aos níveis de contaminação utilizados nas amostras.

Aplicou-se a distribuição “t” de Student ${ }^{1}$, com aproximação normal, no sentido de verificar a ocorrência de possíveis diferenças entre os resultados obtidos e as concentrações reais de $\mathrm{AFM}_{1}$ nas amostras; adotou-se, como nível de rejeição, alfa igual a 0,01 e o valor crítico de " $t$ " de alfa igual a 3,25 para 9 graus de liberdade. Estabeleceram-se, complementarmente, os limites de confiança, para $99 \%$, das médias obtidas nas análises ${ }^{1}$.

A relação entre as concentrações médias obtidas nas análises e as concentrações verdadeiras das amostras foi estabelecida mediante o cálculo do coeficiente de correlação de Pearson, tendo a equação da reta sido determinada mediante a regressão linear simples ${ }^{12}$.

\section{RESULTADOS E DISCUSSÃO}

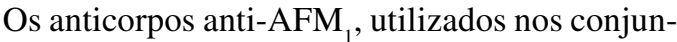
tos VERATOX ${ }^{\mathrm{TM}}{ }^{\circledR}$ são policlonais, produzidos em coelhos imunizados com AFM $_{1}$ conjugados à albumina sérica bovina, reagindo especificamente com o grupo hidroxi-bi-furânico da molécula de $\mathrm{AFM}_{1}{ }^{9}$. Entretanto, podem ocorrer reações cruzadas com outras aflatoxinas, como $\mathrm{AFB}_{1}, \mathrm{AFB}_{2}$ e $\mathrm{AFG}_{1}$. Para estas toxinas, a empresa fabricante dos conjuntos estimou os percentuais de reação cruzada relativa de $73 \%$, $18 \%$ e $39 \%$, respectivamente. Esses valores expressam a relação entre a concentração de AFM $_{1}$ necessária para reagir com 50\% dos anticorpos, e a concentração de outras aflatoxinas necessária para manifestar este mesmo efeito ${ }^{8}$. Contudo, é remota a possibilidade de transferência de resíduos significativos destas aflatoxinas para o leite, com conseqüente interferência nos resultados.

O tempo médio para a execução de cada seqüência analítica, 5 padrões e 5 amostras, foi de aproximadamente 55 min.

Os resultados obtidos nas análises das amostras experimentalmente contaminadas com $\mathrm{AFM}_{1}$ encontram-se listados na Tabela 1. As análises com a amostra número 1 revelaram-se todas negativas para $\mathrm{AFM}_{1}$, o que confirma a ausência desta toxina ou de outros interferentes detectáveis pelo método, no leite em pó utilizado no preparo das amostras.

A Tabela 2 relaciona os parâmetros estatísticos adotados para a avaliação intralaboratorial do desempenho do método ELISA, calculados em relação aos valores da Tabela 1. As concentrações médias obtidas nas análises, quando comparadas às concentrações reais das amostras, indicaram percentuais de recuperação entre $83,0 \%$ (amostra 2, contendo 0,10 $\mathrm{ng} / \mathrm{ml}$ ) e $11,8 \%$ (amostra 5, contendo 1,00 ng/ml). Estes valores encontram-se dentro do esperado, segundo Horwitz ${ }^{10}$ (1982), para análises ao nível de partes por bilhão (ng/ml), ou seja, entre $60-110 \%$ não foram encontradas diferenças entre as concentrações médias e as concentrações reais das amostras, para todos os níveis de contaminação ( $\mathrm{p}>0,01)$, o que atesta a inexistência de erros sistemáticos nos resultados obtidos.

Tabela 1 - Resultados obtidos nas análises realizadas em amostras de leite em pó reconstituído, contaminadas com diferentes concentrações de AFM 1 (ng/ml). São Paulo, 1994.

\begin{tabular}{cccccc}
\hline & \multicolumn{3}{c}{ Concentração de AFM $(\mathrm{ng} / \mathrm{ml})$} \\
\cline { 2 - 6 } Análise & Amostra & Amostra & Amostra & Amostra & Amostra \\
& 1 & 2 & 3 & 4 & 5 \\
\hline 1 & $(0,00)^{*}$ & $(0,10)$ & $(0,20)$ & $0,50)$ & $(1,00)$ \\
\hline 2 & 0,00 & 0,08 & 0,20 & 0,45 & 0,90 \\
3 & 0,00 & 0,06 & 0,15 & 0,49 & 0,98 \\
4 & 0,00 & 0,08 & 0,23 & 0,46 & 1,20 \\
5 & 0,00 & 0,09 & 0,16 & 0,54 & 1,07 \\
6 & 0,00 & 0,21 & 0,11 & 0,54 & 1,40 \\
7 & 0,00 & 0,05 & 0,18 & 0,43 & 1,15 \\
9 & 0,00 & 0,13 & 0,10 & 0,52 & 1,10 \\
10 & 0,00 & 0,01 & 0,17 & 0,58 & 1,30 \\
\hline
\end{tabular}

* Os números entre parênteses indicam as concentrações reais de $\mathrm{AFM}_{1}$ nas amostras, em ng/ml;

** A análise 10 da amostra 1 não foi realizada. 
Tabela 2 - Resultados estatísticos, obtidos durante a avaliação do desempenho do método ELISA em condições experimentais, em amostras de leite em pó contaminadas com diferentes concentrações de AFM, (ng/ml). São Paulo, 1994.

\begin{tabular}{|c|c|c|c|c|c|}
\hline \multirow{3}{*}{ Parâmetro estatístico } & \multicolumn{5}{|c|}{ Amostras } \\
\hline & 1 & 2 & 3 & 4 & 5 \\
\hline & $(0,00)^{*}$ & $(0,10)$ & $(0,20)$ & $(0,50)$ & $(1,00)$ \\
\hline Concentração média (ng/ml) & 0,000 & 0,083 & 0,175 & 0,515 & 1,118 \\
\hline Desvio-padrão (ng/ml) & 0,000 & 0,054 & 0,056 & 0,056 & 0,152 \\
\hline Recuperação média (\%) & - & 83,0 & 87,5 & 103,0 & 111,8 \\
\hline Desvio-padrão relativo (\%) & - & 65,5 & 31,8 & 10,9 & 13,6 \\
\hline Valor de " $\mathrm{t} " * *$ & 0,000 & $-0,989$ & $-1,421$ & 0,844 & 2,449 \\
\hline LC mínimo*** (ng/ml) & 0,000 & 0,027 & 0,118 & 0,457 & 0,961 \\
\hline LC máximo*** (ng/ml) & 0,000 & 0,139 & 0,232 & 0,573 & 1,275 \\
\hline
\end{tabular}

* Os números entre parênteses indicam as concentrações reais de $\mathrm{AFM}_{1}$ nas amostras, em ng/ml;

** Todos os valores de " $\mathrm{t}$ " foram não significantes $(\mathrm{P}>0,01)$;

*** Limite de confiança para $99 \%$.

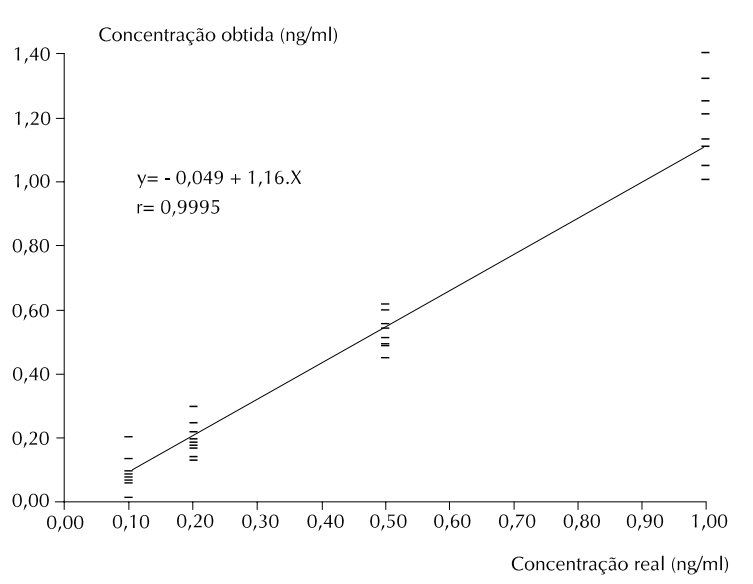

Figura - Relação entre as concentrações médias obtidas nas análises e as concentrações reais das amostras contaminadas experimentalmente com $\mathrm{AMF}_{1}$.

A Figura mostra a relação entre as concentrações médias obtidas e as concentrações reais das amostras, bem como a dispersão dos resultados individuais em torno das médias. Mediante o emprego da regressão linear simples, observou-se uma reta regida pela equação $\mathrm{Y}=-0,049+1,16 . \mathrm{X}$, onde $\mathrm{Y}$ representa a concentração obtida na análise, e $X$, a concentração real de $\mathrm{AFM}_{1}$ na amostra. $\mathrm{O}$ coeficiente de correlação de Pearson (r), entre estas duas variáveis, foi de 0,9995 , o que permite considerar satisfatória a exatidão do método.

O desvio-padrão relativo (DPR), ou coeficiente de variação, é uma medida de variabilidade que reflete, de maneira inversamente proporcional, a precisão do método ${ }^{5}$. A precisão, por outro lado, varia de acordo com a concentração da substância pesquisada. Deste modo, quanto menor a concentração, maior o valor do DPR ${ }^{5}$. Os conjuntos de reativos utilizados foram desenvolvidos para a análise de
$\mathrm{AFM}_{1}$ no leite, considerando-se o limite de tolerância adotado nos Estados Unidos da América (0,5 ng/ $\mathrm{ml})^{22}$. De fato, o método revelou melhor precisão nas análises efetuadas com a amostra 4 , contendo $\mathrm{AFM}_{1}$ neste nível, cuja recuperação média foi de $103,0 \%$ e o DPR igual a $10,9 \%$.

A "Association of Official Analytical Chemists" (AOAC), a respeito da repetibilidade do método de ELISA qualitativo para a análise de $\mathrm{AFB}_{1}$, ao nível de $15 \mu \mathrm{g} / \mathrm{kg}$, recomenda que o valor do DPR não deva exceder a $20,0 \%{ }^{21}$. Dentro deste critério, o método avaliado mostrou-se satisfatório, também, para o nível de 1,00 ng/ml (amostra 5), cujo DPR foi de $13,6 \%$, porém, não nos níveis de 0,10 e $0,20 \mathrm{ng} / \mathrm{ml}$. Horwitz $^{10}$ (1982), por outro lado, afirmou que, em análises ao nível de $1 \mathrm{ng} / \mathrm{ml}$, é possível esperar que os resultados gerados em um mesmo laboratório apresentem, normalmente, valores DPR entre 15,0 $40,0 \%$. Com base neste critério, o qual revela-se mais adequado para a análise de $\mathrm{AFM}_{1} \mathrm{em}$ leite, o método de ELISA demonstrou desempenho satisfatório para concentração entre $0,20-1,00 \mathrm{ng} / \mathrm{ml}$.

Considerando que as amostras foram submetidas diretamente ao ensaio, sem qualquer tratamento prévio, além do fato das análise terem sido repetidas pelo mesmo analista, é possível concluir que a variabilidade dos resultados obtidos foi devida, basicamente, às características dos conjuntos e à execução dos ensaios. De acordo com Ward e Morgan ${ }^{28}$ (1991), os principais fatores que podem diminuir o grau de precisão dos ensaios ELISA incluem: erros no procedimento da análise, pipetagem e preparação dos reagentes imprecisas, homogeneização deficiente das soluções; diferenças entre as microcubetas por cobertura dos anticorpos; e, diferenças entre os conjuntos utilizados.

De acordo com $\operatorname{Scott}^{20}$ (1989), a maioria dos métodos que utilizam a CCD para análise do leite, 
apresenta, para níveis de $0,10-1,00 \mathrm{ng} / \mathrm{ml}$, percentuais de recuperação entre 80,0 - $120,0 \%$, e DPR intralaboratorial entre 10,0 - 30,0\%. Os métodos por CLAR são os que revelam parâmetros de desempenho mais satisfatórios, com recuperação próxima de $100,0 \%$ e DPR, geralmente, abaixo de $10,0 \%{ }^{20}$.

O desempenho do método de ELISA para níveis de 0,20 - 1,00 ng/ml, portanto, pode ser comparado aos métodos tradicionais de análise por CCD. Para o nível de $0,50 \mathrm{ng} / \mathrm{ml}$, o método avaliado apresentou parâmetros próximos aos dos métodos por CLAR.

Pestka e col. ${ }^{19}$ (1981) avaliaram o método de ELISA, pesquisando $\mathrm{AFM}_{1}$ em amostras de leite artificialmente contaminadas, submetidas diretamente ao ensaio, observando, para concentrações de 0,25 $5,00 \mathrm{ng} / \mathrm{ml}$, percentuais de recuperação entre 80,0 $124,0 \%$, para o produto "in natura", e entre 94,0 $120,0 \%$, para o desnatado. Porém, o método não foi capaz de detectar concentrações iguais ou abaixo de $0,10 \mathrm{ng} / \mathrm{ml}$.

A comparação dos resultados obtidos no presente estudo, com o de outros pesquisadores, é dificultada pelo fato de que, na grande maioria, os diferentes métodos imunoenzimáticos para $\mathrm{AFM}_{1}$, mencionados, utilizam procedimentos de purificação das amostras, previamente à execução dos ensaios ${ }^{18}$. Deste modo, com a retirada dos interferentes da amostra, os níveis de detecção podem ser drasticamente reduzidos, situando-se entre 0,002 - 0,10 ng/ $\mathrm{ml}^{7}$, ou seja, abaixo dos níveis adotados no presente trabalho. Com a adoção de procedimentos de purificação, a precisão dos métodos, também, é melhorada, embora com prejuízo para uma das principais vantagens do ELISA: simplicidade de execução ${ }^{8}$.

Os parâmetros estatísticos, adotados no presente estudo, comprovaram a confiabilidade dos resultados originados pelo método de ELISA. No entanto, os métodos analíticos são, usualmente, avaliados com base em outros atributos importantes, sobretudo a aplicabilidade e a praticabilidade ${ }^{10}$.

Tendo em vista a simplicidade de execução e, sobretudo, a possibilidade de utilização do ensaio diretamente nas amostras, o método de ELISA AFM revelou-se bastante prático, embora o custo por análise seja ligeiramente superior ao dos métodos por CCD.

A importância de cada atributo depende da finalidade que se pretende para o método em questão. Nas análises de monitoramento ou nas que envolvam procedimentos de fiscalização, a praticabilidade é muito importante, porém, é secundária em relação à confiabilidade do método ${ }^{10}$. Conseqüientemente, a exatidão e a precisão do método devem ser suficientemente elevadas de maneira a detectar a substância pesquisada em uma determinada concentração. Deste modo, o método de ELISA mostrou-se adequado para tal propósito, considerando níveis de $\mathrm{AFM}_{1}$ a partir de $0,5 \mathrm{ng} / \mathrm{ml}$ de leite em pó reconstituído.

A praticabilidade, no entanto, é fundamental em levantamentos ao nível de campo, onde se faz necessária a análise de grande número de amostras no menor prazo possível. Neste contexto, os resultados do presente trabalho demonstraram bom desempenho do método de ELISA em concentrações de 0,20 - 1,00 ng/ml, o qual pode ser aplicado, sobretudo, em pesquisas de campo sobre a ocorrência de $\mathrm{AFM}_{1}$. É recomendável, porém, que esse método seja submetido, também, a estudos interlaboratoriais, para a corroboração destes resultados.

\section{AGRADECIMENTOS}

Ao Laboratório de Controle de Qualidade da Nestlé Ind. \& Com. Ltda, pela análise da toxina; a "Sigma Chemical Company", pelo fornecimento do padrão $\mathrm{AFM}_{1}$; à "Neogen Corporation", pela cessão dos reativos.

\section{REFERÊNCIAS BIBLIOGRÁFICAS}

\author{
1. BERQUÓ, E.S.; SOUZA, J.M.P.; GOTLIEB, S.L.D. \\ Bioestatística. São Paulo, EPU, 1981. \\ 2. CHU, F.S. Immunoassays for analysis of mycotoxins. $J$. \\ Food Protec., 47:562-9, 1984.
}

3. CULLEN, J.M.; RUEBNER, B.H.; HSIEH, L.S.; HYDE, D.M.; HSIEH, D.S.P. Carcinogenicity of dietary aflatoxin $\mathrm{M}_{1}$ in male Fisher rats compared to aflatoxin $\mathrm{B}_{1}$. Cancer Res., 47:1913-7, 1987.
4. DELLA ROSA, H.V. Determinação de resíduos de aflatoxina $M_{1}$ em leite por fluordensitometria. São Paulo, 1979. [Dissertação de Mestrado - Faculdade de Ciências Farmacêuticas da USP].

5. DUX, J.P. Handbook of quality assurance for the analytical chemistry laboratory. New York, Van Nostrand Reinhold, 1986.

6. FOOD AND AGRICULTURE ORGANIZATION. Manuals of food quality control: the food control laboratory. Rome, 1986. (FAO Food and Nutrition Paper, 14/1). 
7. FRÉMY, J.M. \& CHU, F.S. Direct enzyme-linked immunosorbent assay for determining aflatoxin $\mathrm{M}_{1}$ at picogram levels in dairy products. J. Assoc. Off. Anal. Chem., 67: 1098-101, 1984.

8. FRÉMY, J.M. \& CHU, F.S. Immunochemical methods of analisis for aflatoxin $\mathrm{M}_{1}$. In: Van Egmond, H.P., ed. Mycotoxins in dairy products. London, Elsevier Applied Science, 1989. p. 97-125.

9. HARDER, W.O. \& CHU, F.S. Production and characterization of antibody against aflatoxin $\mathrm{M}_{1}$. Experientia, 35: 11046, 1979.

10. HORWITZ, W. Evaluation of analytical methods used for regulation of foods and drugs. Anal. Chem., 54:67A-76A, 1982.

11. HSIEH, D.P.H. An assessment of liver cancer risk posed by aflatoxin $\mathrm{M}_{1}$ in the Western world. In: Lacey, J., ed. Trichothecenes and other mycotoxins. New York, John Wiley \& Sons, 1985, p. 521-8.

12. JOHNSON, R. \& BHATTACHARYYA, G. Statistics, principles and methods. New York, John Wiley \& Sons, 1987.

13. KOELTZOW, D.E. \& TANNER, S.N. Comparative evaluation of commercially available aflatoxin test methods. J. Assoc. Off. Anal. Chem., 73:584-9, 1990.

14. MÄRTLBAUER, E.; DIETRICH, R.; TERPLAN, G. Erfahrungen bei der Anwedung von Immunoassay zum Nachweis von Mykotoxinen in Lebensmitteln. Arch. Lebens. Hyg., 42:3-6, 1991.

15. ORGANIZACIÓN PANAMERICANA DE LA SALUD. Micotoxinas. Washington, 1983. (Critérios de Salud Ambiental, 11).

16. PARK, D.L.; MILLER, B.M.; HART, L.P.; YANG, G.; MCVEY, J.; PAGE, S.W.; PESTKA, J.J.; BROWN, L.H. Enzyme-linked immunosorbent assay for screening aflatoxin $\mathrm{B}_{1}$ in cottonseed products and mixed feed: collaborative study. J. Assoc. Off. Anal. Chem., 72:326-32, 1989.

17. PARK, D.L.; MILLER, B.M.; TRUCKSESS, M.W.; NESHEIM, S., VEKICH, A., BIDIGARE, B.; MCVEY, J.L.; BROWN, L.H. Visual and semiquantitativa spectrophotometric ELISA screening method for aflatoxin $\mathrm{B}_{1}$ in corn and peanut products: follow-up collaborative study. J. Assoc. Off. Anal. Chem., 72:638-43, 1989.
18. PESTKA, J.J.; ABOUZIED, M.N.; SUTIKNO. Immunological assays for mycotoxin detection. Food Techonol., 49:1208, 1995.

19. PESTKA, J.J.; LI, Y.; HARDER, W.O.; CHU, F.S. Comparison of radioimmunoassay and enzyme-linked immunosorbent assay for determining aflatoxin $\mathrm{M}_{1}$ in milk. J. Assoc. Off. Anal. Chem., 64:294-3011, 1981.

20. SCOTT, P.M. Methods for determination of aflatoxin $M_{1}$ in milk and milk products - a review of performance characteristics. Food Addit. Contam., 6:283-305, 1989.

21. SCOTT, P.M. Natural poisons. In: Helrich, K. ed. Official methods of analysis of the Association of Official Analytical Chemists. $1^{\text {th }}$ ed. Arlington, Association of Official Analytical Chemists (AOAC), 1990. v.2, p.1184-213.

22. STOLOFF, L.; VAN EGMOND, H.P.; PARK, D.L. Rationales for the establishment of limits and regulations for mycotoxins. Food Addit. Contam., 8:213-22, 1991.

23. STUBBLEFIELD, R.D. \& VAN EGMOND, H.P. Chromotographic methods of analysis for aflatoxin $\mathrm{M}_{1}$. In: Van Egmond, H.P., ed. Mycotoxins in dairy products. London, Elsevier Applied Science, 1989. p. 57-95.

24. TROPICAL DEVELOPMENT AND RESEARCH INSTITUTE. Micotoxin training manual. London, TDRI, 1984.

25. TRUCKSESS, M.W.; STACK, M.E.; NESHEIM, S.; PARK, D.L.; POHLAND, A.E. Enzyme-linked immunosorbent assay of aflatoxins $B_{1}, B_{2}$ and $G_{1}$ in corn, cottonseed, peanut butter and poultry feed: collaborative study. J. Assoc. Off. Anal. Chem., 72:957-62, 1989.

26. VAN EGMOND, H.P. Aflatoxin $\mathrm{M}_{1}$ : ocurrence, toxicity, regulation. In: Van Egmond, H.P., ed. Mycotoxins in dairy products. London, Elsevier Applied Science, 1989. p. 11-55.

27. WAKHISI, J. Exposure of rat offsprings to aflatoxin risks through suckling mothers dosed with aflatoxin $\mathrm{B}_{1}$. J. Toxicol. Toxin. Rev., 8:275-80, 1989.

28. WARD, C.M. \& MORGAN, M.R.A. Reproducibility of a commercially available kit utilizing enzyme-linked immunosorbent assay for determination to aflatoxin in peanut butter. Food Addit. Contam., 8:9-15, 1991.

29. WOOD, G.E. Aflatoxin M $M_{1}$ In: Sharma, R.P. \& Salunkhe, D.K., eds. Mycotoxins and phytoalexins. Boca Raton, CRC Press, 1991. p. 145-64. 